\title{
CARACTERIZAÇÃO DE SISTEMAS SILVIPASTORIS DA REGIÃO NOROESTE DO ESTADO DO PARANÁ
}

\author{
Aline Nikosheli Nepomuceno ${ }^{1}$, Ivan Crespo Silva ${ }^{2}$ \\ ${ }^{1}$ Eng $^{\text {a }}$. Florestal, M.Sc., Universidade Tuiuti do Paraná, Curitiba, PR, Brasil - aline.nepomuceno@ gmail.com \\ ${ }^{2}$ Eng. Florestal, Dr., Depto. de Ciências Florestais, UFPR, Curitiba, PR, Brasil - ivancrespo@ufpr.br
}

Recebido para publicação: 07/05/2008 - Aceito para publicação: 16/09/2008

\begin{abstract}
Resumo
A implantação de sistemas silvipastoris na região noroeste do Paraná é um meio de controlar processos de degradação do solo frequentes na região, além de otimizar o uso da terra. No presente trabalho, foram avaliadas 43 propriedades distribuídas nos municípios das microrregiões de Umuarama e Cianorte, com o objetivo de caracterizar e avaliar os SSPs utilizados. Utilizaram-se revisão e análise crítica da literatura e visitas às propriedades rurais para realização de entrevistas com os proprietários e observações no campo. Obtiveram-se dados relacionados à área ocupada por SSP nas propriedades avaliadas. As modalidades mais difundidas na região são o plantio do componente arbóreo em curvas de nível, formando renques em nível com linha simples ou linha dupla, plantio em renques sem orientação definida e a formação de bosquetes, sendo que dentre as espécies florestais mais difundidas estão a Grevillea robusta e espécies do gênero Eucalyptus. Como conclusão, tem-se que os sistemas silvipastoris na região noroeste do Paraná ainda não desempenham todas as suas potencialidades, principalmente porque o potencial madeireiro não é aproveitado economicamente.
\end{abstract}

Palavras-chave: Sistema silvipastoril; pastagem; noroeste do Paraná.

\begin{abstract}
Characterization of silvopastoral systems on the northwest region of Paraná State. The implantation of silvopastoral systems is a way to control the frequently erosive process in the region and also can optimize the use of the land. In this research, they were evaluated 43 properties spread in the counties of the microregion of Umuarama and Cianorte with the objective of characterizing and to evaluate the SPS in the region. For this, it was used revision and critical analysis of literature and visits to the farming to realize interviews with the owners and field observation. It was gotten data related to the areas having SPS in the properties evaluated. The spread out modalities of the region are plantation of trees in the contour line, forming simple or double rows, plantation in rows without orientation defined and the formation of bosquets, being that amongst spread out forest species are Grevillea robusta and species of the Eucalyptus genus. As conclusion the silvopastoral systems in the northwest region of Paraná still not accomplish all its potentialities because the lumber potential is not used economically.
\end{abstract}

Keywords: Silvopastoral systems; pasturage; Grevillea robusta.

\section{INTRODUÇÃO}

Desde o início da colonização do estado do Paraná, a prática de atividades agropecuárias contribui decisivamente para seu desenvolvimento econômico. Ao longo dos anos, a modernização da agricultura ocasionou um aumento da produção, entretanto, o uso inadequado de recursos naturais levou a um processo de degradação ambiental, contribuindo para o empobrecimento do setor rural. Como 
resultado dessa situação, os produtores da região noroeste do estado do Paraná vêm procurando controlar os processos erosivos frequentes na região, por meio dos sistemas silvipastoris (SSPs).

Os sistemas silvipastoris, uma modalidade dos sistemas agroflorestais (SAFs), são associações naturais, planejadas ou convertidas de pastagens com espécies arbóreas, com potencial para promover melhor aproveitamento dos recursos naturais e resultar em maior diversidade produtiva na propriedade rural.

A região noroeste do estado do Paraná, caracterizada por uma economia quase que exclusivamente rural, necessita ter seus fatores de produção devidamente identificados e caracterizados, para que toda a potencialidade presente possa ser desenvolvida.

O presente trabalho teve por objetivo caracterizar e avaliar os SSPs utilizados na região noroeste do Paraná, quantificar e caracterizar as áreas com SSPs nas propriedades e determinar a frequência e a condição das espécies presentes nos sistemas de produção das propriedades.

\section{MATERIAL E MÉTODOS}

\section{Área de estudo}

O estado do Paraná divide-se em mesorregiões geográficas, sendo estas divididas em microrregiões geográficas. A mesorregião geográfica Noroeste Paranaense compreende a microrregião geográfica Paranavaí, Umuarama e Cianorte. A região estudada abrange 32 municípios da microrregião de Cianorte e Umuarama.

Os solos presentes na região são originados do Arenito Caiuá e apresentam alta suscetibilidade à erosão, baixa retenção de água e deficiência de fertilidade. A textura arenosa associada à ocorrência de altas temperaturas leva à excessiva e rápida mineralização da matéria orgânica (MAURINA; BUBLITZ, 2001).

A implantação de qualquer sistema de produção agrícola deve respeitar a natureza desses solos e suas características naturais, bem como os elementos componentes do clima.

\section{Procedimentos metodológicos}

Do total de municípios da região, foram visitados treze, sendo eles: Alto Piquiri, Cafezal do Sul, Cianorte, Cidade Gaúcha, Cruzeiro do Oeste, Esperança Nova, Guaporema, Iporã, Ivaté, Nova Olímpia, São Manoel do Paraná, Tapejara e Xambrê. Os municípios foram selecionados por apresentarem propriedades com SSPs, conforme cadastro regional da EMATER-PR.

A variação no número de entrevistas está relacionada à existência e ao número de sistemas por município. Em alguns casos havia a indicação de apenas um sistema por localidade, sendo que a grande maioria se concentrou em Cianorte, Tapejara e Cruzeiro do Oeste.

Para as entrevistas, foram utilizados questionários fechados abrangendo questões sobre área, espécie e manejo de pastagem, o componente arbóreo, sanidades e sua finalidade, espécie bovina e finalidade, principal produção, quadro de funcionários, histórico da área e da implantação do sistema. As únicas respostas livres foram em relação aos motivos que levaram o produtor a optar por um SSP e as diferenças observadas após a sua implantação.

\section{RESULTADOS}

\section{Área ocupada com sistemas silvipastoris nas propriedades}

Do total de municípios analisados, as maiores concentrações de área com SSPs encontram-se nos mesmos municípios com as maiores frequências de propriedades com SSPs: Tapejara com 143,39 ha, Cruzeiro do Oeste com 135,19 ha e Cianorte com 151,1 ha.

Dentre as 43 propriedades avaliadas, observou-se que $88,4 \%$ possuem a área total dividida em outras funções, além do sistema silvipastoril. Entre as atividades mais difundidas, estão culturas agrícolas variadas, pecuária extensiva tradicional e outras criações de animais, principalmente sericultura. área.

Dessa forma, do total de propriedades avaliadas, somente 5 implantaram o SSP na totalidade da

\section{Implantação dos sistemas silvipastoris nas propriedades}

A implantação inicial dos SSPs ocorreu sem muito critério técnico, muitas vezes por herança das linhas de Grevillea robusta Cunn. utilizadas para sombreamento do café, economia de destaque na região até meados da década de 1960. Assim, com o passar do tempo e orientações pontuais do serviço de extensão rural, esses sistemas foram sendo adaptados às características da região, tornando-se prática comum nas propriedades. 
Dessa maneira, a implantação dos sistemas ocorre, em geral, dentro de duas possibilidades: com o plantio das árvores e das forrageiras quando a introdução das árvores é feita por ocasião da renovação de pastagens, ou em áreas anteriormente ocupadas com agricultura, em conformidade com Carvalho et al. (2002).

Nesses casos, o plantio das mudas de árvores pode ser inicialmente associado com culturas anuais, retardando-se a semeadura das forrageiras por 1-2 anos, o que contribui para evitar a necessidade de proteção das mudas quando o plantio dos dois componentes é simultâneo.

Em relação aos sistemas estudados, em $61 \%$ das propriedades a implantação ocorreu por ocasião da reforma da pastagem, quando o período que antecede a implantação da pastagem, recomendado para o cultivo de culturas anuais, é aproveitado para o plantio das espécies florestais. O restante, correspondente a $39 \%$ dos SSPs, ocorreu durante o processo de substituição de cultura, sendo que, destes, $35 \%$ das propriedades utilizavam sua área para cultivo de café e apenas $3 \%$ com o cultivo de milho.

No período que antecede a implantação do sistema, $52 \%$ dos produtores optaram pelo cultivo de plantas anuais, sendo elas milho, mamona, mandioca e sorgo, isoladas ou em rotação. O cultivo de café foi a escolha de $6 \%$ dos produtores, conforme a tabela 1.

Tabela 1. Cultura agrícola utilizada no período de implantação do sistema silvipastoril.

Table 1. Agricultural culture used on the implantation time of silvopastoral system.

\begin{tabular}{lc}
\hline Cultura & \% \\
\hline Pasto & 42 \\
Milho & 13 \\
Mamona & 3 \\
Mandioca & 11 \\
Mandioca e milho & 13 \\
Milho e algodão & 3 \\
Milho e sorgo & 3 \\
Sorgo & 6 \\
Café & 6 \\
\hline Total & 100 \\
\hline
\end{tabular}

Esses resultados evidenciam que os proprietários deixam de usufruir do potencial do sistema, pois as culturas anuais poderiam ser mais efetivamente plantadas durante o período de implantação do pasto, no qual não há presença dos animais.

\section{Modalidades de sistemas silvipastoris identificados}

Do total de propriedades avaliadas, foram identificados $74,4 \%$ de SSPs organizados, isoladamente, na modalidade "renques em nível com linha simples" (Figura 1), conforme tabela 2. O plantio em curvas de nível é prática comum na região, como resultante de práticas de controle da erosão. Muitos sistemas são originários de plantações de café, dispostas no campo com a mesma finalidade, das quais, após a erradicação dos cafeeiros sombreados, restaram as árvores remanescentes que hoje compõem muitos dos SSPs presentes na região.

As faixas dos renques apresentam espaçamentos não padronizados, entre árvores variando de $1 \mathrm{a}$ 5 metros e entre linhas de 20 a 40 metros, dependendo da inclinação do terreno. O espaçamento predominante, no entanto, é de 2 metros entre árvores e de 20 metros entre linhas.

A percepção é de que os "renques em nível com fila simples" são efetivos no controle da erosão, contribuindo ainda para a redução do trânsito dos animais na pastagem, uma vez que eles passam a caminhar mais ao longo das fileiras de árvores, ou seja, em nível. Esse hábito contribui para minimizar o surgimento de trilhas no sentido da pendente do terreno, onde ocorre concentração do escorrimento superficial e o surgimento de sulcos de erosão, o que está em conformidade com Silva e Mazuchowski (1999).

Por outro lado, observou-se, de maneira geral, que os renques direcionam os animais às linhas, fato que causa danos ao sistema radicial das árvores, expondo as raízes ao tempo. Dessa maneira, o efeito do pisoteio do gado sobre o solo pode ser evidenciado como uma limitação aos sistemas silvipastoris, conforme Schneider; Galvão; Longhi (1978), que verificaram que o pisoteio intensivo causa acentuado desnudamento da superfície do solo e destrói as raízes superficiais das árvores, provocando, ainda, compactação e consequente diminuição da porosidade do solo. 


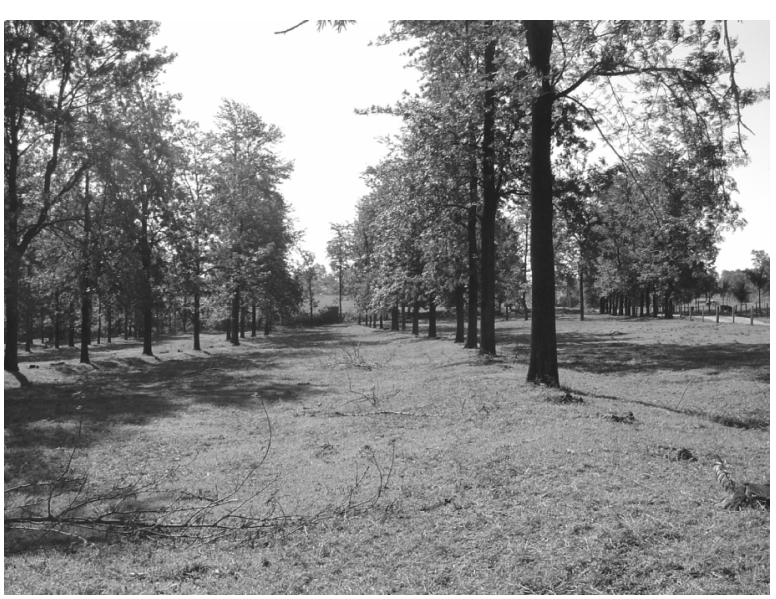

Figura 1. Modalidade "renques em nível com linha simples".

Figure 1. Modality "contour line with simple row".

Tabela 2. Modalidades de sistemas silvipastoris encontrados.

Table 2. Modalities of silvopastoral system found.

\begin{tabular}{lcc}
\hline Modalidade & Frequência & \% de utilização \\
\hline Renques em nível/bosquetes & 1 & 2,3 \\
Renques em nível/renques & 1 & 2,3 \\
2 filas/renques em nível & 2 & 4,7 \\
Renques & 2 & 4,7 \\
Bosquetes & 5 & 11,6 \\
Renques em nível & 32 & 74,4 \\
\hline Total & 43 & 100 \\
\hline
\end{tabular}

A funcionalidade em termos de abrigo para os animais está em função da distância de projeção da sombra, sendo que, no entorno das árvores que são plantadas na crista das curvas de nível e onde há exposição de raízes, o gado apenas trafega induzido pela condição desfavorável do ambiente. Espaçamentos maiores, nesse tipo de sistema, possibilitariam melhor aproveitamento (conforto térmico) do ambiente pelos animais.

De maneira isolada, a modalidade "bosquetes" (Figura 2) foi observada em 11,6\% das propriedades. Essa prática, no geral, é decorrente dos programas de fomento florestal desenvolvidos pelo governo do estado do Paraná e órgãos ambientais a partir de 1987 (SILVA; MAZUCHOWSKI, 1999).

Figura 2. Modalidade "bosquete".

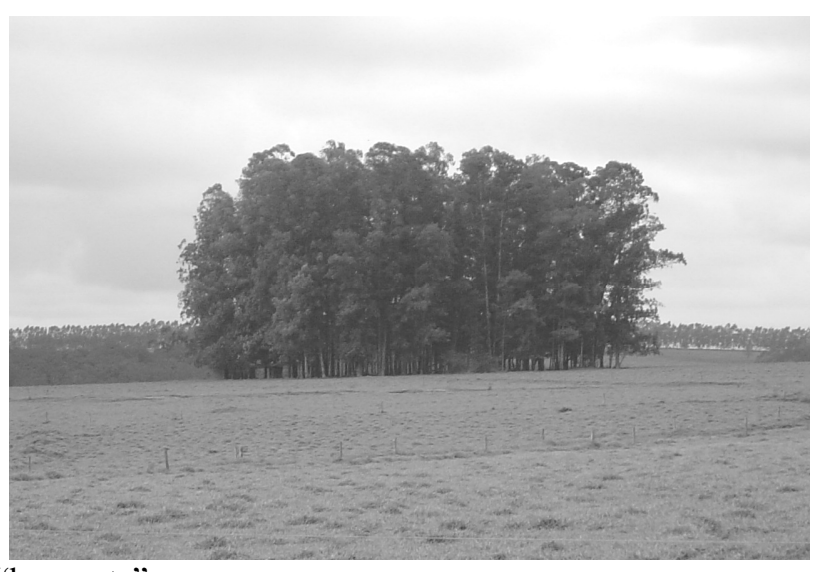

Figure 2. Modality "bosquets". 
Do ponto de vista florestal, o "bosquete" é uma modalidade com grande potencial de exploração madeireira e de manejo sustentado em SSPs, pois possibilita a rotação em talhões de diferentes idades, potencializando, assim, a produção sustentável de madeira.

Adicionalmente, os "bosquetes", devido às características do seu arranjo de campo e à semelhança com os talhões de produção florestal, possibilitam maior flexibilidade de manejo para fins madeireiros.

Os "bosquetes" apresentam alta densidade de plantas, não permitindo o adequado desenvolvimento do pasto no seu interior. Esse aspecto poderia ser alterado se houvesse a implantação de espaçamentos maiores entre as plantas, que pudessem garantir tanto o abrigo dos animais quanto o desenvolvimento de pastagens.

O plantio em "renques simples" (sem orientação definida) foi identificado em 4,7\% das propriedades, e o plantio em "renques em nível com linha dupla" (Figura 3) também foi observado em $4,7 \%$ das propriedades.

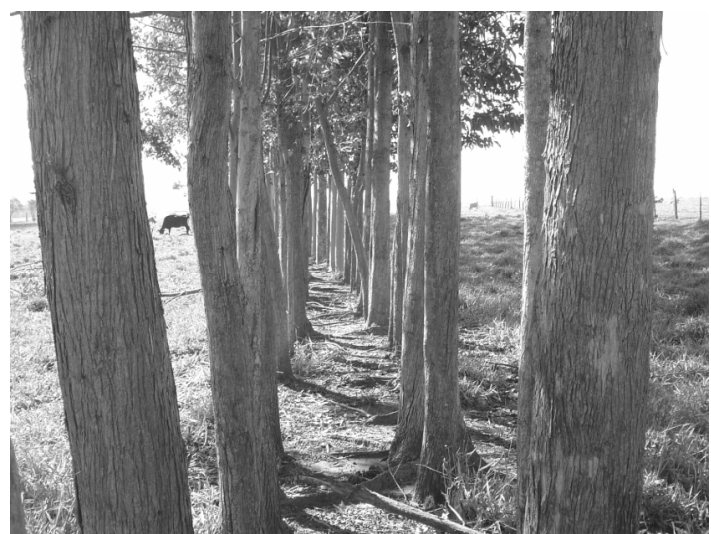

Figura 3. Modalidade "renques em nível com linha dupla".

Figure 3. Modality "contour line with double row".

O plantio "renques em nível com linha dupla" ocasiona maior competição entre as árvores, devido à grande densidade de plantas entre linhas (espaçamento médio de 1 metro). Observou-se também a exposição de raízes ao longo das linhas.

A consequência desses fatores adversos é o menor valor comercial das árvores para fins madeireiros, pois o plantio é bastante desuniforme em termos de crescimento e desenvolvimento, apresentando DAPs variados. Quanto à funcionalidade, é semelhante ao observado na modalidade "renques em nível com linha simples". áreas.

Deve-se ressaltar que 9,3\% das propriedades utilizam mais que uma modalidade de SSP em suas

\section{Espécies florestais avaliadas nos sistemas silvipastoris}

A utilização de espécies arbóreas adaptadas e com características adequadas é uma condição essencial para a implantação e sustentabilidade do SSP. De modo geral, a seleção das espécies florestais que compõem o SSP é feita em relação à rapidez de crescimento para suportar a pressão de pastejo do gado.

Do total de propriedades, foram identificados 14 estabelecimentos com plantio monocultural de Eucalipto (Eucalyptus sp.) (Tabela 3), porém 24 propriedades apresentaram plantios compostos pelo gênero Eucalyptus combinado com outros gêneros de árvores, totalizando 55,8\% em relação ao número de ocorrências nas propriedades.

Com relação ao gênero Eucalyptus, ocorre uma grande variedade de espécies entre as propriedades, numa mesma área e também na mesma linha, principalmente na modalidade "renques em nível com linha simples".

A grevílea (Grevillea robusta) é a espécie mais difundida nos SSPs da região estudada. Ocorre em $60,5 \%$ das propriedades, sendo $30,2 \%$ de forma monocultural, $11,6 \%$ em associação com o Eucalyptus sp., 4,7\% em associação com a canafístula (Peltophorum dubium Spreng. Taub) e o restante em outras associações. 
Tabela 3. Componente florestal e sua frequência nos sistemas silvipastoris da região noroeste do Paraná.

Table 3. Forestry component and its frequency in the silvopastoral systems on the northwest region of Parana.

\begin{tabular}{lcc}
\hline Espécies & Frequência & \% de utilização \\
\hline Eucalipto & 14 & 32,6 \\
Eucalipto/Canafístula/Gurucaia/Guabiroba & 1 & 2,3 \\
Eucalipto/Ipê-amarelo & 1 & 2,3 \\
Eucalipto/Leucena/Grevílea & 1 & 2,3 \\
Grevílea & 13 & 30,2 \\
Grevílea e Salix & 1 & 2,3 \\
Grevílea/Aroeira/Canafístula & 1 & 2,3 \\
Grevílea/Canafístula & 2 & 4,7 \\
Grevílea/Cinamomo & 1 & 2,3 \\
Grevílea/Eucalipto & 5 & 11,6 \\
Grevílea/Eucalipto/Canafístula/Sibipiruna/Uva-do-japão & 1 & 2,3 \\
Grevílea/Eucalipto/Cinamomo & 1 & 2,3 \\
Leucena & 1 & 2,3 \\
\hline Total & 43 & 100 \\
\hline
\end{tabular}

A espécie grevílea e as espécies do gênero Eucalyptus totalizam 62,8\%, representando maior ocorrência entre as espécies florestais identificadas nos SSPs. Esse alto índice de ocorrência, no caso do eucalipto, deve-se aos programas de fomento florestal e, no caso da grevílea, à indicação do IBC (Instituto Brasileiro do Café) na década de 1970, para a formação de quebra-ventos arbóreos nas lavouras cafeeiras.

A grande difusão da grevílea na região é também devida a fatores como a facilidade de adaptação e o rápido crescimento em diversos tipos de solo e clima, além de estabelecer pouca competitividade com as culturas agrícolas e pastagens e de fornecer benefícios amplamente reconhecidos no meio rural, conforme Martins (2000).

A canafístula (Peltophorum dubium) foi encontrada em 5 propriedades, sempre associada a outra espécie arbórea. Essa espécie, de maneira geral, não desempenha bom papel no sistema, em função de ser uma planta caducifólia, ter copa aberta e baixa densidade foliar, o que explica, provavelmente, a sua baixa adoção entre os produtores.

A leucena (Leucaena leucocephala Lam. de Wit) foi encontrada de maneira isolada em apenas uma propriedade, que tem como produção principal o leite. A espécie permite o pastoreio direto ou o corte de suas folhas e ramos comestíveis, sendo, portanto, utilizada como banco de proteína, fornecendo forragem que complementa o pastoreio na dieta dos animais. Por outro lado, a baixa adoção da leucena pode ser explicada com base no receio que os produtores têm de ela se propagar naturalmente sem controle, devido a essa espécie ser rústica, com grande capacidade de disseminação e competição, o que a caracteriza como planta invasora.

De maneira geral, os SSPs avaliados tem como principal atividade a pecuária, tratando o componente arbóreo apenas como fator auxiliar na produção pecuária. Foram identificadas diferentes finalidades do uso do sistema, sendo que $67,7 \%$ dos produtores apresentaram mais que um objetivo. De maneira geral, $77,4 \%$ dos proprietários se preocupavam com o conforto térmico, garantindo sombra para o gado, conforme figura 4.

O controle de erosão foi a preocupação que levou $48,4 \%$ dos produtores a implantar o sistema. O uso de árvores nas pastagens é uma técnica que auxilia na redução do impacto da chuva no solo através da copa das árvores, pelo aumento e manutenção da matéria orgânica do solo, pela redução do escorrimento superficial e pelo incremento da cobertura do solo com a deposição de folhas das árvores, conforme Baggio (1988).

A produção de madeira correspondeu ao objetivo de $38,7 \%$ das propriedades, e melhorar a paisagem do local, deixando a pastagem mais harmoniosa visualmente, foi o objetivo de $12,9 \%$ dos produtores.

A utilização de árvores como quebra-vento foi o objetivo de 6,5\% dos produtores, sendo que além de proporcionar benefícios às pastagens e ao gado, com a redução da velocidade do vento, reduz-se também a erosão eólica do solo. O controle de incidência de geadas fez parte do objetivo de $3,2 \%$ dos proprietários, pois a presença das árvores reduz a evaporação da umidade do solo. 
A produção de alimento, em particular com o uso da leucena (Leucaena leucocephala), correspondeu ao objetivo de $3,2 \%$ das propriedades.

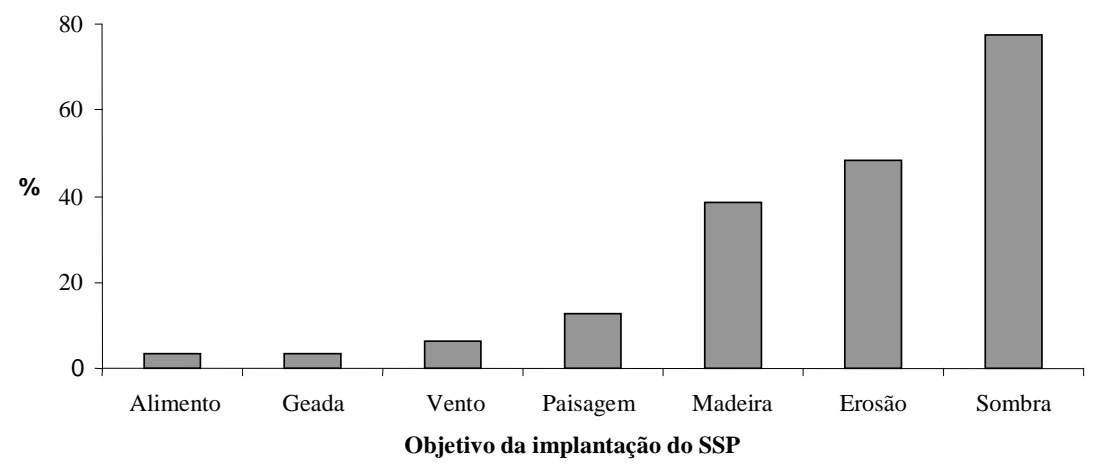

Figura 4. Objetivo da implantação do sistema silvipastoril nas propriedades da região noroeste no Paraná. Figure 4. Objective of implantation the silvopastoral system in the properties of the northwest region of Paraná.

Com relação ao aproveitamento da madeira de maneira plena, há necessidade de conduzir o plantio com podas planejadas e desbastes, o que não ocorreu nos estabelecimentos visitados. Do total de propriedades, apenas $58 \%$ dos produtores faz algum tipo de manejo, como poda, desbaste e adubação, sendo que o restante não intervém no desenvolvimento das árvores.

Do total de propriedades avaliadas, apenas 8 já exploraram economicamente o componente florestal, porém outros produtores declararam que ocasionalmente cortam algumas árvores para consumo próprio.

De modo geral, não possuem planejamento da produção, portanto a periodicidade da colheita está mais ligada à necessidade da madeira no mercado local, sendo que a madeira é comercializada "em pé" para a produção de lenha e para abastecer as serrarias locais.

\section{Pastagens}

A tolerância ao sombreamento varia entre as forrageiras, logo, esse é um quesito na seleção de espécies para uso em SSPs. Dentre as mais utilizadas no Brasil, Brachiaria decumbens Stapf, Brachiaria brizantha Hochst Stapf e Panicum maximum são consideradas tolerantes ao sombreamento (CARVALHO; XAVIER; ALVIM, 2001).

Em relação aos gêneros observados nas propriedades, considerando que algumas pastagens são cultivares híbridos, a frequência com que ocorrem isoladas ou consorciadas com outras pastagens foi de 48,3\% para o gênero Brachiaria, seguida, na mesma condição, pelo gênero Cynodon (30\%), Panicum (13,3\%), Paspalum (5\%) e Axonopus (3,3\%), conforme figura 5.

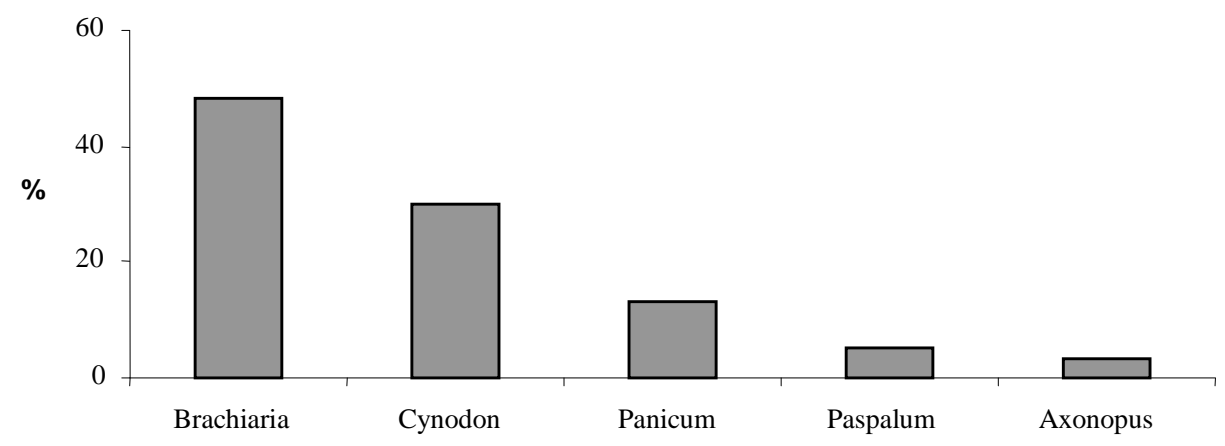

Gênero das forrageiras

Figura 5. Gênero das forrageiras encontradas nas propriedades da região noroeste do Paraná.

Figure 5. Forages genus found in the properties of northwest region of Paraná. 
Dentre as espécies de pastagens observadas nas propriedades analisadas, as de maior freqüência, isoladas ou em consórcios, são: brachiaria (Brachiaria decumbens) com participação relativa de 27,9\% em relação ao total das propriedades avaliadas, seguida pelo capim estrela (Cynodon nlemfuensis var nlemfuencis), em 27,9\% e pelo brizantão (Brachiaria brizantha), presente em 25,6\% das propriedades (Tabela 4).

Tabela 4. Espécie forrageira e sua ocorrência nos SSPs da região noroeste do Paraná.

Table 4. Forages species and its occurrency in the SSPs of northwest region of Parana.

\begin{tabular}{lccc}
\hline Espécie & Nome popular & Ocorrência absoluta & $\begin{array}{c}\text { Participação relativa } \\
(\%)\end{array}$ \\
\hline Brachiaria decumbens Stapf & Brachiaria & 12 & 27,9 \\
Cynodon nlemfuensis var nlemfuensis & Capim-estrela & 12 & 27,9 \\
Brachiaria brizantha Hochst Stapf & Brizantão & 11 & 25,6 \\
Panicum maximum cv. mombaça & Mombaça & 7 & 16,3 \\
Cynodon plectostachyus & Estrela-roxa & 4 & 9,3 \\
Paspalum notatum Flüegge & Mato-grosso & 3 & 7,0 \\
Axonopus compressus (Sw.) P. Beauv. & Grama-missioneira & 2 & 4,7 \\
Brachiaria brizantha cv. MG-5 & MG5 & 2 & 4,7 \\
Brachiaria brizantha cv. MG4 & MG4 & 2 & 4,7 \\
Brachiaria humidicola Rendle & Humidícola & 2 & 4,7 \\
Cynodon dactylon cv. Coastcross & Coast-cross & 1 & 2,3 \\
Cynodon nlemfuensis Vanderyst & Tifton & 1 & 2,3 \\
Panicum maximum cv.tanzania & Tanzania & 1 & 2,3 \\
\hline
\end{tabular}

Do gênero Brachiaria, destaque para a espécie $B$. decumbens, que é utilizada em termos absolutos em 12 propriedades, isolada ou consorciada com outra pastagem, representando $27,9 \%$ das pastagens, sendo que a $B$. brizantha ocorreu em $25,6 \%$ das propriedades. O gênero Brachiaria é considerado tolerante ao sombreamento moderado e por isso é muito difundido entre os SSPs.

As plantas desse gênero adaptam-se a variadas condições de solo e clima, mas a sua expansão deveu-se principalmente à adaptação de diversos cultivares a condições de solos com baixa e média fertilidade, proporcionando produções satisfatórias de forragem.

O gênero Cynodon adapta-se a grande variedade de solos, desde os arenosos até os argilosos pesados, preferindo os levemente úmidos e bem drenados. Desse gênero foram observadas as espécies $C$. nlemfuensis, C. plectostachyus e C. dactylon.

Do total das 43 propriedades analisadas, 14 (32,6\%) utilizam duas ou três pastagens na área, porém em piquetes diferentes.

\section{Componente animal}

Em relação à área total das propriedades avaliadas, a pecuária representa a principal atividade, estando presente em 93,6\% delas; a agricultura, representada pelo cultivo de cana, ocorre em 3,2\%; e a atividade pesqueira (modalidade pesque-pague) responde por 3,2\%.

Quanto ao objetivo da criação de gado na propriedade e no SSP, 53,5\% destinam-se ao comércio de carne, $34,9 \%$ para produção de leite e $2,3 \%$ para ambas as atividades simultaneamente, conforme figura 6 .

Verifica-se, ainda, com pequena participação, a criação animal destinada à venda de reprodutores $(2,3 \%)$ e novilhos $(7 \%)$.

\section{CONCLUSÕES}

Considerando o universo amostral da pesquisa, a metodologia de avaliação realizada e os resultados obtidos, conclui-se:

- Os SSPs encontrados são oriundos de práticas para controle de erosão e representam uma diversificação produtiva da atividade original.

- Os sistemas silvipastoris da região noroeste do Paraná ainda não desempenham todas as suas potencialidades. 
- O potencial madeireiro dos sistemas silvipastoris avaliados não é aproveitado.

- Das modalidades de SSPs avaliados, os "bosquetes" evidenciam maior potencial madeireiro, devido à maior densidade de plantas arbóreas que possibilitam no seu arranjo. A consolidação desse potencial pode se dar com o uso de espaçamento e manejo adequados, de maneira a garantir a produção madeireira, o conforto térmico dos animais e o desenvolvimento de pastagens.

- Brachiaria decumbens e Cynodon nlemfuensis, devido à elevada ocorrência e bom desempenho nos sistemas de produção avaliados, representam boas opções para compor novas práticas silvipastoris na região.

- A principal atividade nos SSPs do Paraná é a pecuária de corte.

- A prática silvipastoril já faz parte da cultura produtiva rural da região.

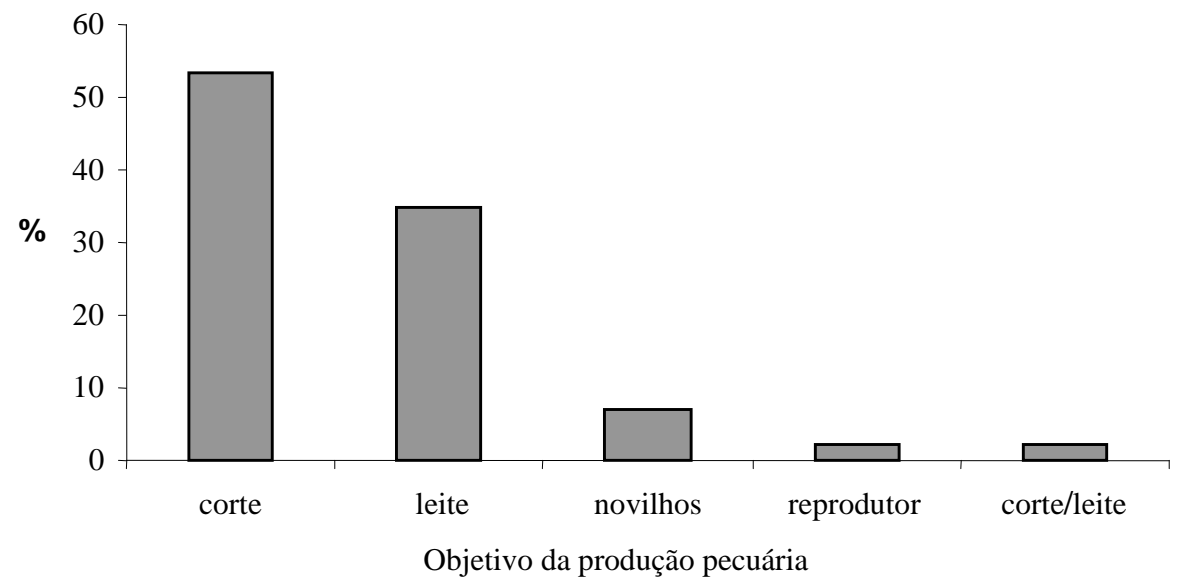

Figura 6. Objetivo principal da pecuária.

Figure 6. Main objective of cattle raising.

\section{REFERÊNCIAS}

BAGGIO, A. J.; CARPANEZZI, O. B. Alguns sistemas de arborização de pastagens. Boletim de Pesquisa Florestal, Curitiba, n. 17, dez 1988.

CARVALHO, M. M.; ALVIN, J. M.; XAVIER, D. F.; YAMAGUCHI, L. C. T. Estabelecimento de sistemas silvipastoris: ênfase em áreas montanhosas e solos de baixa fertilidade. Juiz de Fora: Embrapa Gado de Leite, 2002. 12 p. (Circular Técnica, n. 68).

CARVALHO, M. M.; XAVIER, D. F.; ALVIM, M. J. Características de algumas leguminosas arbóreas adequadas para associação com pastagens. Juiz de Fora: Embrapa Gado de Leite, 2001. 24 p. (Circular Técnica, n. 64).

MARTINS, E. G. Seleção genética e características fisiológicas e nutricionais de procedências de Grevillea robusta (Cunn) estabelecidas no Estado do Paraná. 125 f. Tese (Doutorado em Ciências Florestais) - Setor de Ciências Agrárias, Universidade Federal do Paraná, Curitiba, 2000.

MAURINA, A. C.; BUBLITZ, U. Manejo integrado de solos e água: solos derivados do Arenito Caiuá. Curitiba: EMATER-PR/SERT, 2001. 36 p.

SCHNEIDER, P. R.; GALVÃO, F.; LONGHI, S. J. Influência do pisoteio de bovinos em áreas florestais. Floresta, Curitiba, v. IX, n. 1, p. 19-23, 1978. Disponível em: < http://calvados.c3sl.ufpr.br/ojs2/index.php/floresta/article/view/6209/4426 >. Acesso em: 05/03/2008.

SILVA, V. P. da; MAZUCHOWSKI, J. Z. Sistemas Silvipastoris: paradigma dos pecuaristas para agregação de renda e qualidade. Curitiba: EMATER- PR, 1999. 46 p. 